\title{
Forest area predicts all dimensions of small mammal and lizard diversity in Amazonian insular forest fragments
}

\author{
Ana Filipa Palmeirim (D) Fábio Z. Farneda • Marcus Vinícius Vieira • \\ Carlos A. Peres
}

Received: 6 May 2021/Accepted: 3 August 2021/Published online: 13 August 2021

(C) The Author(s) 2021

\begin{abstract}
Context Although hydropower development is one of the primary drivers of habitat loss and insular fragmentation, its impacts on species identity and their functional and phylogenetic roles have often been overlooked.

Objectives Here we use an integrative approach, considering taxonomic, functional and phylogenetic dimensions at multiple scales, to understand the processes underlying species (dis)assembly of two
\end{abstract}

Supplementary Information The online version contains supplementary material available at https://doi.org/10.1007/ s10980-021-01311-w.

A. F. Palmeirim $(\bowtie) \cdot$ C. A. Peres

Center for Ecology, Evolution and Conservation, School of Environmental Sciences, University of East Anglia,

Norwich NR4 7TJ, UK

e-mail: anafilipapalmeirim@gmail.com

Present Address:

A. F. Palmeirim

CIBIO-InBIO, Universidade do Porto, Campus de Vairão,

Rua Padre Armando Quintas, 4485-661 Vairão, Portugal

F. Z. Farneda

Department of Ecology and Evolution, Federal University of Santa Maria, Santa Maria, RS CEP 97105-900, Brazil

M. V. Vieira

Laboratório de Vertebrados, Departamento de Ecologia, Universidade Federal do Rio de Janeiro, CP 68020,

Rio de Janeiro, RJ CEP 21941-590, Brazil taxa exhibiting relatively low dispersal ability: small mammals and lizards.

Methods We surveyed 26 islands within the Balbina Hydroelectric Reservoir, and adjacent continuous forest, in Central Amazonia. Each dimension of diversity was related to spatial and habitat variables. We also examined functional composition using community-weighted mean trait values, and community redundancy using functional uniqueness. $\beta$ diversity was partitioned into their richness $\left(\beta_{\text {rich }}\right)$ and replacement $\left(\beta_{\text {repl }}\right)$ components.

Results Functional and phylogenetic $\alpha$-diversities of both taxa mirrored the taxonomic dimension, all of which increased with forest area. Individual small mammal (body mass and matrix tolerance), and lizard traits (body length, heliothermic mode and habitat type) were also predicted by forest area. For both groups, functional uniqueness decreased with forest area, and all dimensions of $\beta$-diversity were predominantly partitioned in $\beta_{\text {rich }}$.

Conclusions The environmental filter created by forest area resulted in the low conservation value associated with small forest islands, only occupied by a small set of species comprised by generalist lizards and matrix-tolerant small mammals. On the other side, large forest sites ensured ecosystem resilience to disturbance. To maintain ecosystem integrity, creating myriad small islands over large expanses of floodwaters should be avoided in future hydropower development. 
Keywords Beta-diversity - Community-weighted mean trait values - Environmental filter - Functional diversity · Functional redundancy · Habitat loss and fragmentation · Island biogeography · Phylogenetic diversity

\section{Introduction}

Habitat loss, fragmentation and subsequent degradation are primary drivers of biodiversity loss worldwide (Sala et al. 2000; Haddad et al. 2015). In the tropics, hydropower development is a major cause of habitat loss and fragmentation, often creating vast archipelagic landscapes, in which forest islands are isolated within a uniformly hostile open-water matrix (Jones et al. 2016). In these archipelagic landscapes, island taxa typically experience a novel hyper-disturbance regime, resulting in drastic shifts in species diversity and community composition through species extinction and turnover (Cosson et al. 1999; Gibson et al. 2013; Benchimol and Peres 2015a). Despite the growing number of recent studies showing the pervasive ecological impacts of hydroelectric dams, only a few have employed functional and phylogenetic metrics (Jones et al. 2016). Nevertheless, taxonomic, functional and phylogenetic dimensions of diversity can be simultaneously affected by habitat disturbance (Salgado-Luarte et al. 2019, Aguirre-Gutiérrez et al. 2020), while their study provides complementary information (Graham and Fine 2008, Smiley et al. 2020).

Functional traits reflect environmental preferences and associated behaviours that directly affect species performance, fitness and ecological functions (Violle et al. 2007). Functional diversity therefore incorporates species trait variation that potentially affects species performance, fitness and ecological functions (Weiss and Ray 2019). Phylogenetic diversity integrates the shared ancestry of species in terms of both the amount of evolutionary history and degree at which species are phylogenetically related (Webb et al. 2002; Veron et al. 2017). Since functional traits that allow species to persist in the environment tend to be evolutionarily conserved (i.e. positive phylogenetic signal: Safi et al. 2011), phylogenetic and functional diversity tend to be correlated (Tucker et al. 2018, Rurangwa et al. 2021).
Across fragmented landscapes, larger habitat fragments tend to harbour more species-rich assemblages, eventually accumulating more species traits (Dainese et al. 2015; Farneda et al. 2018). This results in the functional redundancy of those assemblages which are also more resilient to disturbance (Petchey et al. 2007; Ricotta et al. 2016). At the other extreme of the habitat fragmentation gradient, consisting of small habitat fragments harbouring depauperate species assemblages, the combination of the remaining species traits is therefore likely to be more functionally unique. In particular, local species extinctions within those smaller fragments may disproportionally affect ecosystem functioning (Dirzo et al. 2014).

Improving our understanding on how species diversity is organized and maintained following habitat loss and fragmentation further requires going beyond $\alpha$-diversity (within-site) metrics, thereby considering $\beta$-diversity (between sites). While taxonomic $\beta$-diversity reflect differences in species composition between sites (Whittaker 1972), functional $\beta$-diversity discriminates change between communities of taxa with either similar or different functions in the system (Ricotta and Burrascano 2009), and phylogenetic $\beta$ diversity distinguishes between phylogenetically close and distant lineages in evolutionary time (Graham and Fine 2008). Disentangling the contribution of the two components of either of the $\beta$-diversity dimensionsrichness differences and replacement-further enables inference about the mechanisms of species assembly (Meynard et al. 2011). The richness-component denotes differences linked to species losses and gains, or to equivalent differences in functional traits or phylogenetic lineages. The replacement-component indicates differences due to species, traits or lineage replacements from one site to another (Cardoso et al. 2014). In the presence of an environmental filter shaping species assemblages, the richness-component will be more important, but if species colonization and extinction events are random processes, $\beta$-diversity will be mainly partitioned into the replacementcomponent (Carvalho et al. 2012). In the aftermath of habitat loss and fragmentation, forest area decreases, isolation increases (Chase et al. 2020) and overall habitat quality deteriorates (Tabarelli et al. 2008), likely creating an environmental filter to certain species, traits and genetic lineages, which would be sequentially extirpated from smaller sites (Carvalho et al. 2012; Cardoso et al. 2014). 
Here, we examine multi-scale effects of habitat loss and insular fragmentation on the diversity of assemblages of two major vertebrate taxa - small mammals (marsupials and rodents) and lizards - in the Central Amazonian insular landscape of the Balbina Hydroelectric Reservoir, and nearby continuous forest. These vertebrate groups are ecologically diversified in neotropical forests, spanning across the vertical forest strata and occupying multiple trophic niches (Ávila-Pires 1995; Paglia et al. 2012). Both groups are characterized by relatively low dispersal abilities due to their reduced size and non-volant habits. The varied roles played by both groups in natural ecosystemspredators, prey, grazers, seed dispersers and commensal species-are critical for ecosystem functioning, including forest regeneration (Terborgh et al. 2001). Small mammal and lizard assemblages were surveyed across a gradient of habitat loss and fragmentation comprised of 26 islands of different sizes, degrees of isolation and configurations, in addition to control continuous forest sites. We examined patterns and predictors of taxonomic, functional and phylogenetic diversity, functional trait composition and functional redundancy of small mammals and lizard assemblages. Additionally, to elucidate processes underlying species (dis)assembly resulting from habitat loss and fragmentation, we examined the partition of $\beta$ diversity in its two components. Across the insular landscape, we tested the following hypotheses:

(1) Taxonomic, functional and phylogenetic $\alpha$ diversity of both taxa generally increase with island size and habitat quality (i.e. low-intensity edge effects and higher tree species richness) and decrease on more isolated forest islands (MacArthur and Wilson 1967; Meynard et al. 2011).

(2) Traits allowing small mammal and lizard species to persist on small, isolated and habitat-degraded islands will be favoured over the gradient of fragmentation (Devictor et al. 2008). In particular, we expect those traits to be related to higher dispersal ability (e.g. larger body size and overall matrix tolerance) and generalist habits in terms of both habitat (e.g. ability to use of open-habitat areas) and diet (Wang et al. 2010; Farneda et al. 2015).

(3) Impoverished assemblages on small islands have higher assemblage-level functional uniqueness (i.e., mean species-level functional uniqueness) compared to larger islands because the few remaining species have more unique combinations of traits (Ricotta et al. 2016).

(4) Following a reduction in forest area, environmental filtering promotes selective extinction of species, increasing differences in $\beta$-diversity more due the richness-component (Carvalho et al. 2012). The importance of the richnesscomponent is further expected to increase for larger differences in forest area (Cardoso et al. 2014).

\section{Materials and methods}

Study area

Surveys were carried out in the insular landscape of the Balbina Hydroelectric Reservoir and its immediate surroundings in Central Brazilian Amazonia ( $1^{\circ} 48^{\prime} \mathrm{S}$, $59^{\circ} 29^{\prime} \mathrm{W}$; Fig. 1). This landscape was created following the construction of Balbina Dam in 1986 on the Uatumã River, a left-bank tributary of the Amazon River. This dam flooded an area of 312,900 ha of pristine primary forest, within the 443,772-ha hydroelectric reservoir (FUNCATE/INPE/ANEEL 2000). Given the undulating topography, its former hilltops were converted into 3,546 land-bridge islands of varying sizes and configuration. Many dead relics of emergent trees are still standing across the reservoir lake, as the submerged primary forest was never clearcut. Vegetation mostly consists of dense closedcanopy terra firme forest, but many small islands were strongly affected by edge-related windfalls and ephemeral wildfires, which occurred during a late1997 to early-1998 El Niño drought (Benchimol and Peres 2015b). The area within and around the former left bank of the Uatumã river has been legally protected since 1990 by the 942,786-ha Uatumã Biological Reserve, the largest reserve in its category in Brazil, further contributing to the current low human disturbance in this area. Mean annual temperature and mean annual rainfall in this region are $28^{\circ} \mathrm{C}$ and 2,376 mm (IBAMA 1997).

Small mammal and lizard assemblages were sampled on 26 islands (Figs. 1), 24 of which included surveys of both groups, while islands number 22 and 9 


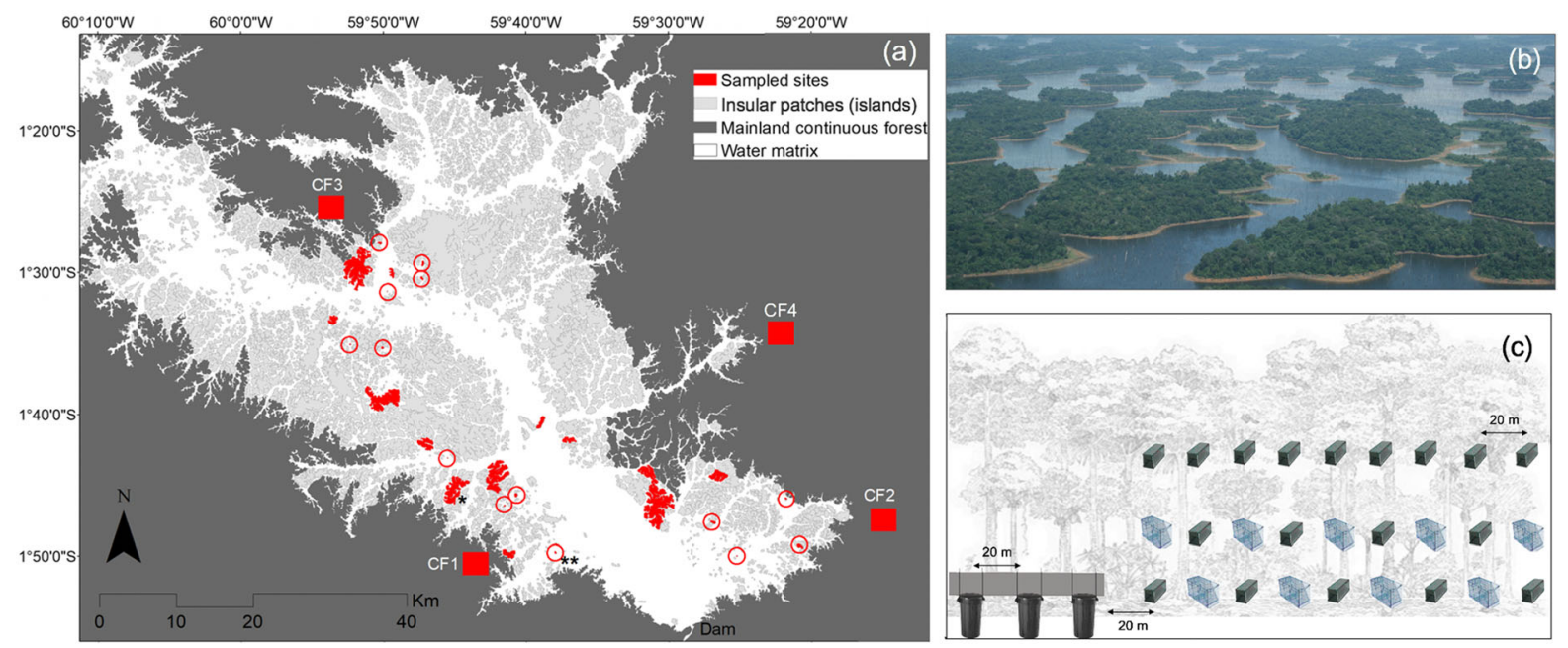

Fig. 1 a Sites where small mammals and lizards were surveyed within the Balbina Hydroelectric Reservoir of Central Brazilian Amazonia: 26 islands (in red and highlighted by a buffer if relatively small) and four continuous forest regions in the mainland $(\mathrm{CF} 1, \mathrm{CF} 2, \mathrm{CF} 3$ and $\mathrm{CF} 4$; indicated by red rectangles); asterisks indicate islands where only small mammals (*) or lizards (**) were sampled. b Aerial view of the Balbina archipelagic landscape (photo credit: E. Venticinque) including the aquatic matrix; c sampling design of each transect: an array of three pitfall-traps followed by nine live-trap stations (i.e., Sherman and wire-mesh traps), each of which including three traps deployed on the forest floor, understorey and (sub)canopy; distances between traps are indicated in the figure

number of CF sites was considerate adequate to obtain a representative sample of the assemblages of both taxa occupying the reservoir area before flooding (Fig. 1).

Small mammal and lizard surveys

Surveys were carried out in two seasons, the first from April to November 2014 and the second from April to November 2015. Each season consisted of a trapping session of 16 consecutive nights/days. To minimise the impact of any eventual seasonal variation, sites were surveyed in the same order in both field seasons. Small mammals were sampled using traplines containing nine stations of live traps (hereafter, LTs) followed by an array of three pitfall units, and lizards were sampled using shorter transects consisting of the same array of three pitfalls. Each LT station was placed 20-m apart from others and included two Sherman traps $(23 \times 9 \times 8 \mathrm{~cm}$, H. B. Sherman Traps, Inc., Tallahassee, Florida) and one wire mesh trap $(30 \times 17.5 \times 15 \mathrm{~cm}$, Metal Miranda, Curitiba, Paraná). At each LT station, one trap was set on the ground, one in the understorey $(\sim 1.5 \mathrm{~m}$ high $)$, and one in the (sub)canopy ( $>10 \mathrm{~m}$ high). Traps of 
different types were placed alternatively on the ground and in the understorey across consecutive stations, but only Sherman traps were placed in the canopy due to logistic limitations. The forest canopy stratum was sampled by placing a trap in a mobile wood platform that was left in contact with the canopy tree branch (Lambert et al. 2006). LTs were baited with a mix of bananas, peanut powder, sardines and oatmeal. Pitfall traps (plastic buckets of $100 \mathrm{~L}$ ) were also spaced by 20-m intervals and connected by a plastic drift fence $50-\mathrm{cm}$ high and $10-\mathrm{cm}$ underground, with $10 \mathrm{~m}$ of fence extending beyond the two terminal pitfalls.

The number of transects placed at different sites varied according to their area. This allowed us to increase sampling size (i.e., number of individuals recorded) in larger forest sites, where trap density and consequently the probability of an individual passing near a trap are lower. Due to spatial restrictions on islands smaller than 2 ha and those between 2 and 10 ha, alternative smaller transects were placed containing three LT stations followed by an array of one pitfall, and by six LT stations followed by an array of two pitfalls, respectively. Larger islands were sampled by as many as four transects, according to their size classes: 10 to 50 ha (one transect), 50 to 200 ha (two), 200 to 500 ha (three), and $>500$ ha (four transects). $\mathrm{CF}$ sites were sampled by either five (lizards: CF2, CF2-riparian and CF4), six (both taxa: $\mathrm{CF} 1$ and CF3) and 10 (small mammals: CF2). In CF4, small mammals were surveyed using 12 transects from which only five included the pitfall trapping component. Due to logistic restrictions, CF2 and CF4 were only sampled during either the first (2014) or second (2015) field season, respectively, which reflects the larger number of transects placed therein (for further details on sampling effort per site, see Table S1).

In total, we surveyed small mammals across 79 trapping transects and lizards across 71 transects, that were accordingly nested within 29 and 30 sampling sites. All traps were inspected daily. All small mammal individuals recorded were weighted, measured, collected a tissue sample (ear tip) and tagged (Fish and Small Animal Tag, size 1; National Band and Tag Co., Newport, Kentucky), so that any subsequent recaptures could be distinguished. During the second field season, we also collected tissue samples of lizards (tail tip) for genetic analyses by carefully removing the tail tip of every individual. This allowed us to distinguish individuals that had been previously captured. As recaptures represented a small fraction of the total number of records $(<2 \%)$, all lizard individuals recorded during either the first or second field season were assumed to have been captured only once. Although tissue samples were collected from both small mammals and lizards, we were not always able to identify at the species-level records at all sites the following small mammals: Proechimys spp. (P. cuvieri and P. guyanensis) and Oecomys spp. 1 ( $O$. roberti and $O$. bicolor); and lizards: Leposoma spp. (L. percarinatum and $L$. guianense), Norops spp. ( $N$. planiceps and $N$. chrysolepis), and Kentropyx spp. (K. calcarata and $K$. altamazonica). For both taxa, congeners within these genera are ecologically very similar (Ávila-Pires 1995; Jones et al. 2009), so we further refer to those taxa as ecospecies. To streamline, we hereafter use species to refer to both species and ecospecies. This study followed the guidelines provided by the American Society of Mammalogists (Sikes 2016), the American Society of Ichthyologists and Herpetologists (Beaupre et al. 2004) and the institutional animal care and use committee of the Federal University of Rio de Janeiro (CEUA-CCS UFRJ 2010).

Spatial and habitat variables

For each surveyed site, we considered (1) island size (area), as the total island area of each focal island $\left(\log _{10} x\right)$; (2) island shape (shape), indicating the intensity of edge effects, measured as the perimeter length to area ratio of each focal island $\left(\log _{10} x\right)$; (3) a proximity (prox) metric to other islands and CF sites, following McGarigal et al. (2012), consisting of the sum of all island areas divided by the squared sum of edge-to-edge distances from each focal island to all islands within a buffer of $500 \mathrm{~m}$ (for small mammals) and $250 \mathrm{~m}$ (lizards) $\left(\log _{10} x+1\right.$; Palmeirim et al. 2017, 2018); (4) the nearest Euclidian distance to the mainland (dist); and (5) the number of tree species $\left(S_{\text {tree }}\right)$, calculated by Benchimol and Peres (2015b) from floristic surveys in 0.25 -ha forest plots within each focal island or mainland site. Spatial variables were calculated using ArcMap 10.1 (ESRI 2018) based on high-resolution multi-spectral RapidEye imagery (5-m resolution with 5-band colour imagery) of the entire study landscape. The habitat variable $S_{\text {tree }}$ was obtained from Benchimol and Peres (2015b). Whenever included in the analysis, CF sites were 
assigned with area values one order of magnitude larger than the largest island (146,600 ha). To streamline, we use forest area to refer to both island area and area of CF sites.

Species traits and phylogeny

Functional traits were selected on the basis of their ecological meaning and interpretation within the context of foraging behaviour and resilience of ecosystems (Dreiss et al. 2015). Small mammal traits-body mass, vertical forest strata, trophic level and degree of matrix tolerance-were obtained from field measurement, available databases (Paglia et al. 2012; Wilman et al. 2014) and grey literature (Malcolm 1991). Lizard traits-body length, thermoregulation mode, type of habitat used and range of prey size-were obtained from Martins (1991) reporting data captured in the same landscape (both within islands and in the surrounding mainland forest), whenever available. We supplemented information on lizard traits by adding data from a comprehensive review of the Brazilian Amazonian lizard fauna (Ávila-Pires 1995). In particular, we did not consider vertical forest strata used by lizards because detection of arboreal species may be underestimated due to the sole use of pitfalls as sampling method. Small mammal vertical forest strata and lizard thermoregulation mode and type of habitat used were the only categorical variables that were further transformed into continuous variables in all subsequent analysis, except in those regarding hypothesis 2 examining different modalities within of each categorical variable. Information on individual traits is detailed in Table S2 (see Tables S3 and S4 for trait values of small mammal and lizard species, respectively).

Phylogenetic trees were obtained using small mammal (Upham et al. 2019) and lizard data (Tonini et al. 2016) available in the VertLife platform (2020). This platform provides a tool that we used to produce distributions of phylogenetic trees containing our recorded species. This tool first trimmed the data to a subset of trees $(N=100)$, and then sampled trees from a chosen pseudo-posterior distribution. For species that were not identified at the species-level, we chose the species with the core of its geographic distribution most centred in our study area, following the distribution maps of IUCN Red List (2020) (small mammals: $P$. guyannensis and $O$. bicolor; lizards: $L$. guianense, N. planiceps, K. calcarata). Phylogenetic data was unavailable for one lizard species (Cercosaura oshaughnessyi, updated to Prionodactylus oshaughnessyi), for which we considered a co-generic species (Cercosaura eigenmanni). Based on the subset of phylogenetic trees obtained for each taxon, we generated an averaged tree using the averageTree function (see averaged phylogenetic trees in Fig. S1), from phytools R package (Revell 2012). Phylogenetic species distances were obtained from the average tree by computing the cophenetic distances for the hierarchical clustering using the 'cophenetic' function from R (R Development Core Team 2017).

\section{Data analysis}

For each clade, observed species abundance corresponds to the sum of the number of either small mammal and lizard individuals recorded at each sampling site during the two field seasons, wherever more than one trapping transect was deployed. Sampling effort sufficiency was previously assessed for each taxon and considered satisfactory, except in the case of lizards at two small islands where only one species was recorded. Despite the lack of sampling representativeness at those two small islands, we still retained those islands in the analyses because trap density therein was much higher $(\sim 0.75$ traps/ha) than on large islands ( $>100 \mathrm{ha}, 0.01-0.06$ traps/ha) and CF sites ( $\sim 0.001$ traps/ha; Table S1) (for detailed explanation on the methods used to evaluate sampling sufficiency and the corresponding values, see Palmeirim et al. 2017, 2018). We excluded two singleton records of two small mammal species (Echimys chrysurus and Makalata didelphoides), which are known to be poorly detected by the traps used in this study. Due to differences in sampling effort between sites, species abundance was previously standardized according to sampling effort applied to each site (see Table S1 for details on sampling effort). All data analyses were performed in R (R Development Core Team 2017).

\section{$\alpha$-Diversity analysis}

Following Ricotta et al. (2016), taxonomic (TD), functional (FD) and phylogenetic (PD) $\alpha$-diversities were correspondingly given by the Simpson and Rao's quadratic entropy functional and phylogenetic indices, 
considering relative species abundances. Higher values of Simpson index, ranging between 0 and 1 , indicate higher species richness and evenness. Rao's quadratic entropy index considers the differences (trait- and phylogenetic-based variance) between species pairs (Botta-Dukát 2005). Both Simpson and Rao's indices are based on the same species pairwise distances and relative species abundances so that Rao's is considered a generalization of Simpson (Botta-Dukát 2005). TD, FD and PD were obtained using SYNCSA R package (Debastiani and Pillar 2012).

To test our first hypothesis, we first checked pairwise correlations between spatial and habitat metrics. When considering all sampled sites (i.e., including CF sites), forest area and the proximity index were highly correlated $(r>0.80)$, further preventing us from including both variables in the same models. Therefore, we decided to analyse the effects of only forest area applying Generalized Linear Models (GLMs). This GLM approach is useful for community data because it can be applied to nonnormal response variables typically used in community-level modelling (Warton et al. 2015). Speciesarea relationships in habitat islands frequently follow a power law (Matthews et al. 2016). We accounted for this potential non-linear relationship by fitting GLMs both including and excluding the quadratic term of forest area, and then comparing their Akaike Information Criteria (AIC: Burnham and Anderson 2002). The quadratic term of forest area was retained in the models regarding all the dimensions of lizard diversity (Table S5) and included in subsequent analyses considering these response variables. Non-linear relationships could also be accounted for by using Generalised Additive Models, which are a non-parametric extension of GLMs, and do not require a linear relationship between the response and the explanatory variables. We previously additionally performed GAMs using a Gaussian error structure, using the $m g c v$ R package (Wood and Wood 2015). The results obtained with GAM, however, were the same as those obtained using GLMs. We therefore decided to retain the simplest statistical approach, GLMs, which further allowed us to account for potential non-linear relationships (Matthews et al. 2016). Given that two of the 20 small mammal and three of the 17 lizard species could only be identified at the genus-level, possibly inflating FD or PD over TD, we ran these models with area and its quadratic term considering response variables without these species (Table S6). As no differences in the results were observed, we ran models including all species in subsequent analysis.

We then analysed the combined effects of spatial and habitat variables-area, prox, shape, dist and $S_{\text {tree }}$ - on the $\alpha$-dimensions of small mammal and lizard diversity using GLMs. This second modelling was restricted to the 25 islands surveyed, thereby excluding CF sites. To control for additional high levels of variable inter-dependence, we performed a Pearson correlation matrix. When excluding CF sites, shape was highly correlated with area $(r>0.75)$, but consistently explained less variance than area (Table S7) and was removed from subsequent analyses. A candidate model set was further constructed, using all combinations of the four explanatory variables retained (including the null model with only intercept and residual variance, without explanatory variables), and models were ranked based on their AIC values corrected for small sample sizes (AICc: Burnham and Anderson 2002), using the MuMIn R package (Bartoń 2016). A model-averaging approach was then performed to account for model uncertainty in multimodel inference, using all alternative models (Burnham and Anderson 2002).

\section{Functional trait composition}

Patterns of functional composition were analysed individually considering each small mammal and lizard trait and calculating its community-weighted mean value (CWM: Lavorel et al. 2008), which was obtained considering relative species abundance using the functcomp function of the R package FD (Laliberté and Legendre 2010). By incorporating species relative abundance, CWM ensures assessments of shifts in mean trait values across the range of spatial and habitat-related variables considered (Lavorel et al. 2008). As before, we first analysed forest area effects on each species trait for each taxon considering all sampled sites, by applying GLMs using a Gaussian error structure. Again, to account for any potential non-linear relationship, all GLMs were fitted both including and excluding the quadratic term of forest area, and their AIC were compared (Burnham and Anderson 2002). The quadratic forest area term was retained in models regarding lizards body length (Table S8) and included in all subsequent analyses 
considering this response variable. Then, we analysed the combined effects of all four uncorrelated spatial and habitat variables (area, shape, dist and $S_{\text {tree }}$ ) restricting the analysis to the 25 surveyed islands. A model-averaging approach was then performed as above, to account for model uncertainty in multimodel inference, using all alternative models (Burnham and Anderson 2002).

\section{Functional uniqueness}

To understand the importance of each small mammal and lizard species in supporting a certain function at each sampled site and whether this varied over the range of forest areas, we calculated functional uniqueness at both the species- $\left(K_{i}\right)$ and assemblage-levels $\left(\bar{K}_{i}\right)$. In particular, $K_{i}$ summarises the functional contribution of a single species to the overall redundancy of either the small mammal or lizard assemblage. This metric is given by the mean (functional) distance of a given species from all other species in the assemblage in terms of their functional traits weighted by species abundance (Ricotta et al. 2016). Higher $K_{i}$ values indicate a greater distinction of a given species from all other species in the assemblage. The $K_{i}$ calculations were performed with the uniqueness function provided by Ricotta et al. (2016). We were unable to calculate $K_{i}$ for small mammal species on island 3, and lizards on islands 1, 2, 3, 4 and 26, where only one species of either taxa had persisted. Those sites were therefore excluded from subsequent analyses. Then, to test our hypothesis that functional uniqueness increases on smaller forest islands, we considered the $\bar{K}_{i}$ given by the average of $K_{i}$ across all species in a given site. The effect of forest area on $\bar{K}_{i}$ was evaluated by a GLM with a Gaussian distribution and retaining the forest area quadratic term whenever this improved model fit (i.e., AIC > 2) (Table S9). To further improve model fitting, we removed from the analyses examining variation in $\bar{K}_{i}$ two clear outliers of small mammals (islands 2 and 7) and one lizard (island 8). When related to forest area, these three islands presented much lower $K_{i}$. For example, $\bar{K}_{i}$ of small mammals $( \pm \mathrm{SD})$ was $0.32 \pm 0.11$, while these values for islands 2 and 7 were 0.08 and 0.02 , respectively. After removing these outliers, the $\mathrm{R}^{2}$ increased from 0.02 to 0.40 . Likewise, $\bar{K}_{i}$ of lizards was $0.39 \pm 0.06$, island 8 had 0.26 and its removal increased the $\mathrm{R}^{2}$-value from 0.02 to 0.18 . Thus, these outliers likely corresponded to highly discrepant observations. On those islands, although multiple species were recorded, one species dominated the local assemblage. Given the overall reduced number of individuals recorded on those islands, we consider that those had been potentially affected by sampling limitation. To investigate whether $\bar{K}_{i}$ per site differed significantly between small mammals and lizards, we considered all sites in which both taxa were cosampled (24 islands and $4 \mathrm{CF}$ sites) and applied a paired $t$-test. Secondly, to investigate whether $K_{i}$ followed the pattern observed for $\bar{K}_{i}$ across the range of forest areas, we analysed individual species $K_{i}$ across the range of forest areas. To do so, we considered six small mammal and five lizard species occurring in at least 15 sites, to reach sampling sufficiency, and applied a GLM with a Gaussian distribution, retaining the forest area quadratic term whenever this improved model fits (Table S10).

\section{$\beta$-Diversity analysis}

Our fourth hypothesis, regarding processes underlying community (dis)assembly across the range of forest areas, was examined using $\beta$-diversity partitioning into its richness differences $\left(\beta_{\text {rich }}\right)$ and replacement $\left(\beta_{\text {repl }}\right)$ components (Carvalho et al. 2012). Calculations of PD and FD were based on Faith (1992) and Petchey and Gaston (2002), respectively, which measure PD and FD of a community as the total branch length of a tree linking all species represented in such community. For each dimension, $\beta$-diversity was then partitioned by computing the species incidence data using a sites $\times$ species matrix with the Jaccard dissimilarity index. Functional and phylogenetic pairwise dissimilarity matrices in all analyses were calculated using Gower's distance. We did not use the functional space (instead of functional dendrograms) as this requires the number of species at each site to be higher than the number of traits (Baselga and Orme 2012), and that would preclude us from including smaller islands. We therefore recommend caution in comparing our results on betadiversity whenever another diversity metric is used (Maire et al. 2015). $\beta$-diversity analyses were conducted using the beta function of the R package BAT (Cardoso et al. 2015). Finally, the correlation between 
differences in forest area and $\beta$-diversity and its components were analysed using a Mantel test considering the Spearman coefficient.

\section{Results}

Based on 65,520 trap-nights and 5,447 trap-days, we recorded a total of 884 small mammals (20 species: 10 marsupials and 10 rodents) and 1,123 lizards (17 species), respectively. Islands on average $( \pm \mathrm{SD})$ harboured $5.8 \pm 3.8$ small mammal species (1-16 species) and $5.2 \pm 3.2$ lizard species (1-11), while more species-rich assemblages were observed in mainland continuous forest sites (small mammals: $5.0 \pm 2.5$ species, 9-16; lizards: $9.3 \pm 1.4$ species, $8-11)$.

\section{a-Diversity}

TD, FD and PD of both small mammals and lizards increased significantly $(P<0.005)$ with forest area
(Fig. 2; Table S11). Considering the additional spatial (prox and dist) and habitat-related variables $\left(S_{\text {tree }}\right)$ and restricting the analysis to only 25 surveyed islands, all three dimensions of small mammal diversity were consistently predicted by changes in area (Tables S12 and S13).

\section{Functional trait composition}

Considering all sampling sites, changes in functional trait composition of small mammals and lizards were partly associated with forest area. In particular, largerbodied small mammal species $(P=0.010)$ exhibiting low matrix tolerance $(P=0.034)$ primarily occupied larger forest areas (Fig. 3a-b; Table S14). Lizard assemblages in large forest areas had larger body length (area: $P=0.015$, area $^{2}: P=0.006$ ) (Fig. 3c), were mostly heliophobic in terms of thermoregulation $(P=0.071$, Fig. 3d) and more likely to use riparian habitats (stream banks and waterlogged areas, $P=0.020$ ) rather than open-habitats (forest edges (a)

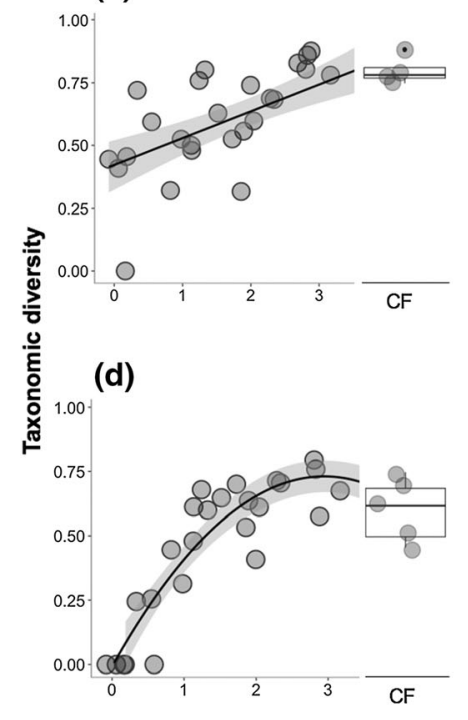

(b)

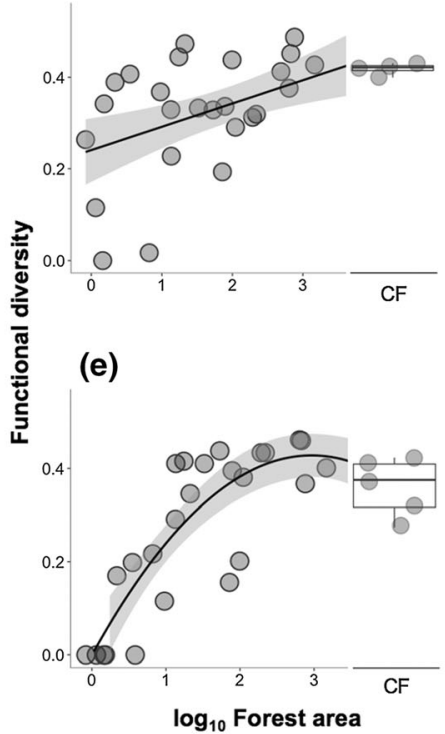

(c)

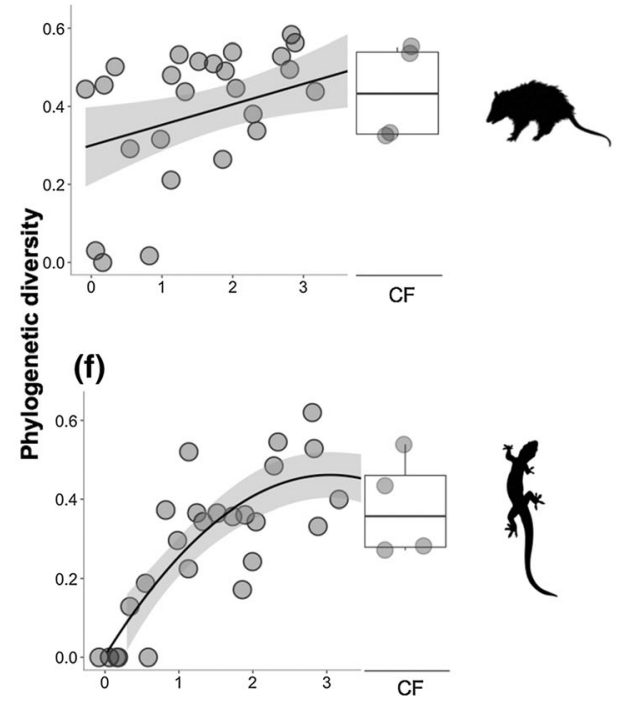

Fig. 2 Relationships between taxonomic (a, d), functional (b, e) and phylogenetic diversity (c, f) with forest area-islands $\left(\log _{10} x\right)$ and continuous forest sites $(\mathrm{CF})$ - for small mammals (upper panels) and lizards (lower panels) at the Balbina Reservoir landscape. Taxonomic diversity is given by the Simpson index and functional and phylogenetic diversities are given by the Rao Quadratic entropy indices. Lines represent the model adjusted for the strongest relationships $(P \leq 0.05)$, and shaded areas represent the $95 \%$ confidence region. Boxplots for CF sites indicate the median, 1 st and 3 rd quartiles, and minimum and maximum values of each diversity metric 
(a)

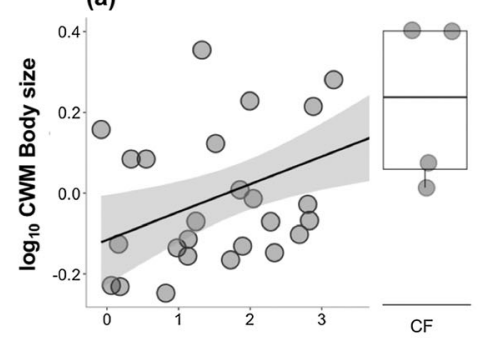

(b)

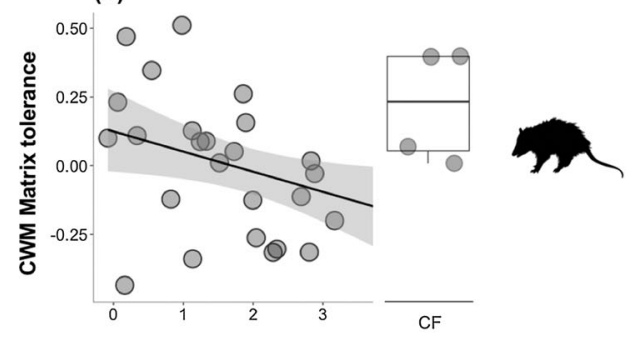

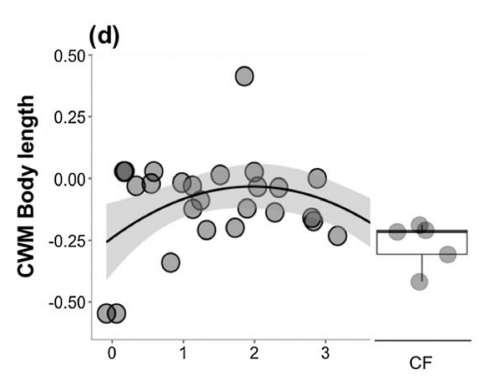
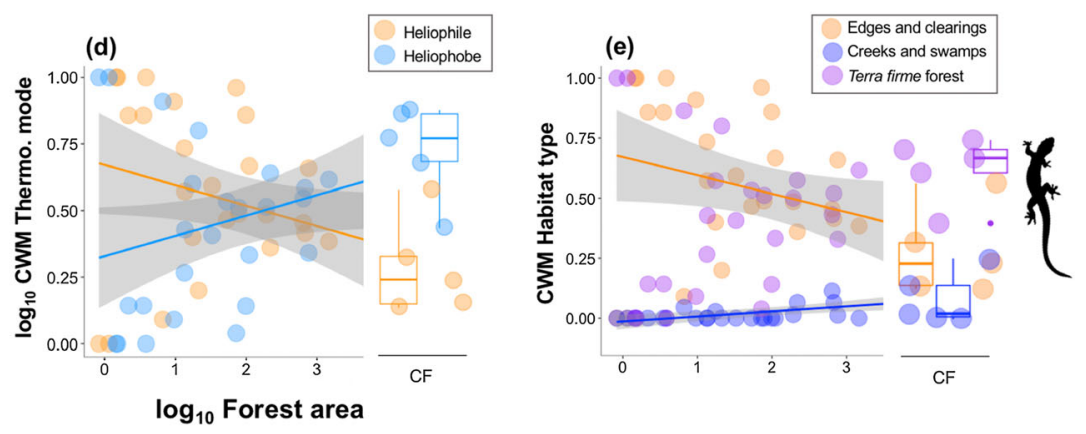

Fig. 3 Relationship between community-weighted mean $(\mathrm{CWM})$ trait values (y-axes) and forest area-islands $\left(\log _{10} \mathrm{x}\right)$ and continuous forest sites (CF) (x-axes) - for small mammals and lizards in the Balbina Reservoir landscape. Results are shown for statistically significant functional traits. Small mammal traits include a body mass and $\mathbf{b}$ matrix tolerance; lizard traits include $\mathbf{c}$ body length, $\mathbf{d}$ thermoregulation mode

and clearings, $P=0.071$ ) (Fig. 3e; Table S14). When accounting for the combined effects of spatial and habitat variables across islands only, matrix tolerance of mammals increased on more isolated islands (lower prox, $P=0.065$ ) (Tables S15 and S16). Larger-bodied lizard species (longer body length, $P=0.050$ ) consuming larger prey $(P=0.054)$ were associated with higher tree diversity, while the positive effect of island area was further reinforced on lizards occupying riparian habitats $(P=0.036)$ (Tables $\mathrm{S} 15$ and $\mathrm{S} 16)$.

\section{Functional uniqueness}

Species-level functional uniqueness $\left(K_{i}\right)$ revealed important functional roles of some small mammal and lizard species over the full range of forest areas. For example, M. murina was the most functionally unique small mammal, which was consistent across most of the sites where they were detected (Fig. 4a). For lizards, several species presented high functional uniqueness across the spectrum of forest areas (e.g., Kenthropyx sp., A. reticulata and T. agilis; Fig. 4b) (categories: heliophobe and heliophile) and e habitat type (categories: creeks/swamps, edges/clearings, and terra firme forest). Lines represent the model adjusted for the strongest relationships (approx. $P \leq 0.05$ ), and shaded areas represent the $95 \%$ confidence region. Results for all traits are provided in Table S14

and their $K_{i}$ was on average $( \pm \mathrm{SD})$ higher $(0.392 \pm 0.064)$ than that of small mammals $(0.317 \pm 0.111 ; t=-3.505, P=0.002)$. Nevertheless, mean $\bar{K}_{i}$ increased towards smaller areas for both small mammals $(P=0.009$ and, for the quadratic term, $P=0.058)$ and lizards $(P=0.036)$ (Fig. 5; Table S17). When considering the six small mammal and five lizard species occurring in at least 15 survey sites, this trend was confirmed for the marsupial Philander opossum $(P=0.001)$ and the lizards Leposoma sp. $(P=0.013)$, Ameiva ameiva $(P=0.034$ and, for the quadratic term, $P=0.017)$ and Plica umbra $(P=0.015)$ (Table S18).

\section{$\beta$-Diversity}

For small mammals, consistently across all dimensions, $\beta_{\text {repl }}$ reduces with differences in forest area, whereas $\beta_{\text {rich }}$ increases. For reptiles, both $\beta_{\text {repl }}$ and $\beta_{\text {rich }}$ increase with differences in forest area (Fig. 6). In particular, the negative trend of $\beta_{\text {repl }}$ of small mammals is generally 
(a)

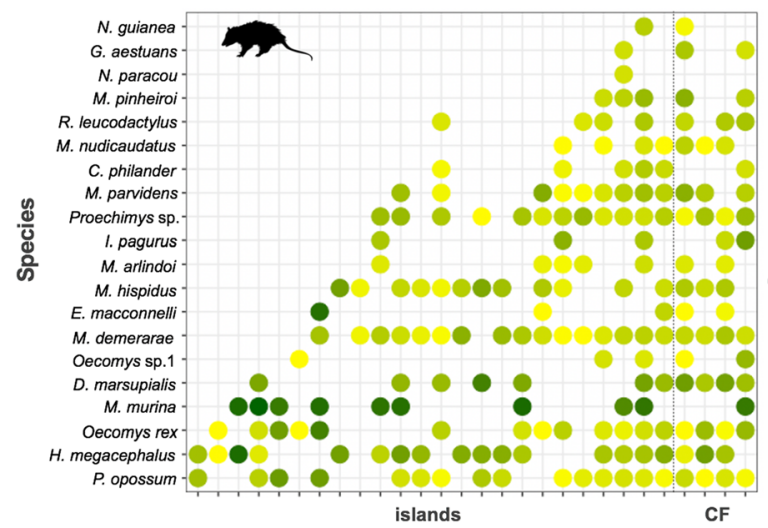

Fig. 4 Species-level functional uniqueness for small mammals (a) and lizards (b) at 29 and 30 sampled sites, respectively, in the Balbina Reservoir landscape. Values of functional uniqueness are indicated by the colour of each dot representing the presence (b)

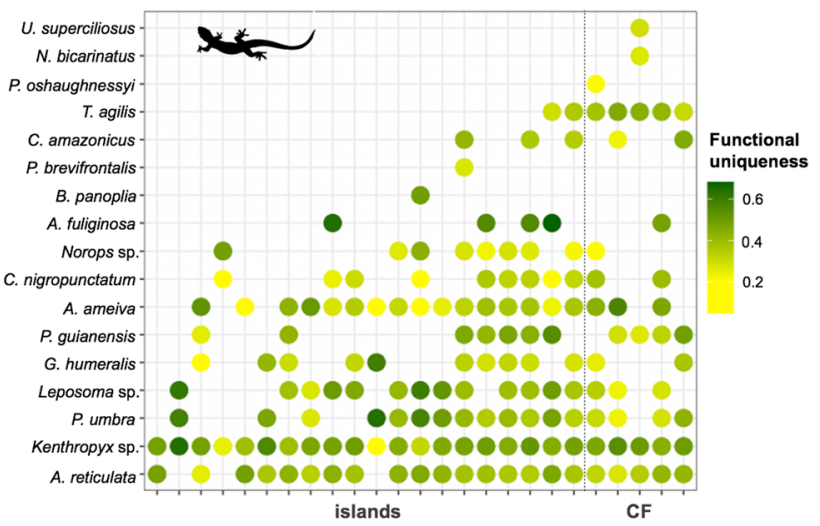

of a certain species at a certain site. Islands are ordered in ascending size; $\mathrm{CF}$ indicates continuous forest sites. Sites where only one species was recorded were excluded from the analysis (small mammals: $N=1$, lizards: $N=5$ ) (a)

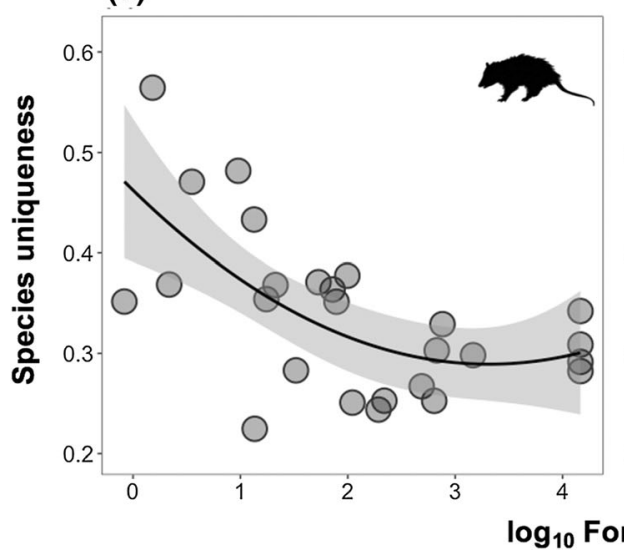

(b)

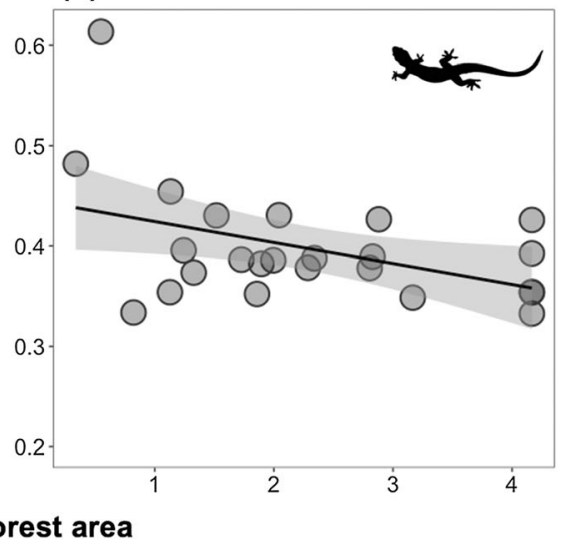

Fig. 5 Relationship between assemblage-level functional uniqueness and forest area $\left(\log _{10} \mathrm{x}\right)$ for small mammals (a) and lizards (b) in the Balbina landscape. Sites where only one species was recorded were excluded from the analysis

non-significant (only significantly negative for taxonomic $\beta$-diversity); for lizards, the positive $\beta_{\text {repl }}$ is nonsignificant only for functional diversity (Table S19).

\section{Discussion}

Insular habitat fragmentation following river damming rapidly drives local species extinctions (Gibson et al. 2013, Jones et al. 2016). Here we show that such (lizards: $N=4$ ). Lines represent the model adjusted for the stronger relationships (approx. $P \leq 0.05$ ), and shaded areas represent the $95 \%$ confidence region

taxonomic loss is followed by severe decay in both functional and phylogenetic diversity for both small mammals and lizards. Species persistence on smaller forest islands depended on traits related to dispersal ability. That was clearly the case of small mammals characterized by a larger body size and higher matrix tolerance, and lizards exhibiting a heliophile thermoregulation mode and preference for open habitats (edges and clearings). Also, despite the overall higher species-level functional uniqueness associated with lizards, assemblage-level functional uniqueness was 
(a)

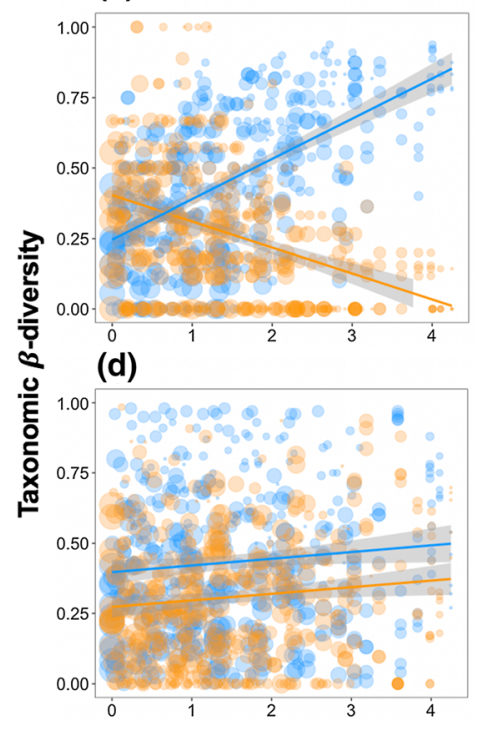

(b)

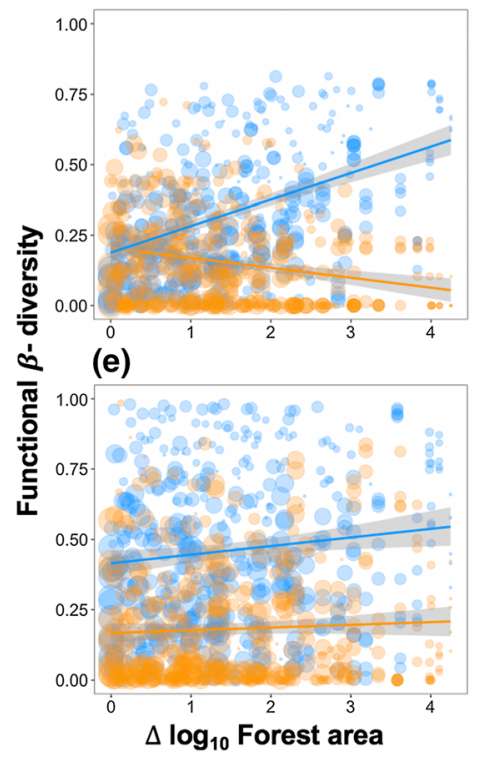

(c)

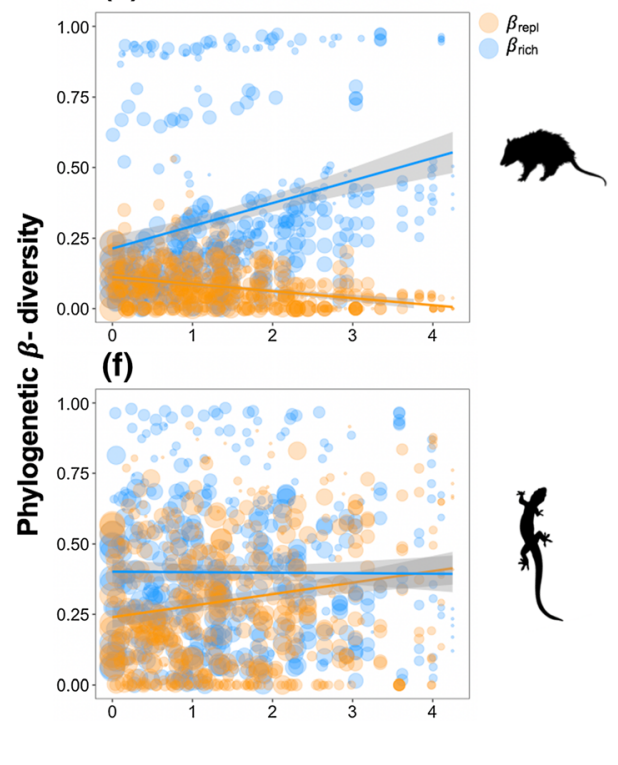

Fig. 6 Relationship between each of the two components of taxonomic (a, d), functional (b, e) and phylogenetic $\beta$-diversity $(\mathbf{c}, \mathbf{f})$-richness differences $\left(\beta_{\text {rich }}\right)$ and replacement $\left(\beta_{\text {repl }}\right)$ - and differences in forest area $\left(\log _{10} x\right)$ for all pairwise combinations of sites. We considered 29 and 30 sites where small mammals (upper panels) and lizards (lower panels) were surveyed, respectively, across the Balbina Reservoir landscape. Circles are sized according to the area of the smaller site within each site pair. Trend lines are indicated for all relationships, and shaded areas represent the $95 \%$ confidence region higher for both taxa on smaller forest islands. Across the gradient of fragmentation, assemblages were predominantly shaped by environmental filtering, as noted by the overall prevalence of the richnesscomponent of $\beta$-diversity. For small mammals, however, species extinction and colonization across either small or large sites were, due to random processes or environmental heterogeneity that was not considered in this study (higher taxonomic $\beta_{\text {repl }}$ where $\Delta$ forest area was particularly low; Fig. 6).

Forest area effects on $\alpha$-diversity and individual species traits

All three metrics of $\alpha$-diversity (taxonomic, functional and phylogenetic) in small mammals and lizards changed predictably with forest area, which is consistent with our expectations (Petchey et al. 2007, Meynard et al. 2011, Rurangwa et al. 2021). Given the expected intercorrelation between these three dimensions of diversity (Tucker et al. 2018), our results suggest that considering either taxonomic, functional or phylogenetic diversity may be sufficient to predict others (Safi et al. 2011, Dreiss et al. 2015). A consistently positive relationship between TD, FD and PD with forest area was similarly observed in subtropical reservoir islands for bird (Si et al. 2017) and ant assemblages (Zhao et al. 2020), and for small mammals across the Brazilian Atlantic Forest biome (Bovendorp et al. 2019).

Individual trait responses further suggest that small mammal species community membership across the insular fragmented landscape is mainly related to their ability to persist on habitat-degraded small islands, rather than isolated sites. For instance, larger forest areas were more likely to support larger-bodied small mammal species. Community body mass averaged $140 \mathrm{~g}$ on the four small islands $(<2 \mathrm{ha})$, but $401 \mathrm{~g}$ at the four continuous forest sites. This is at odds with our initial hypothesis that larger body size confers higher physical endurance in traversing the open-water matrix, which finds support in diverse vertebrate taxa, including small mammals (Cosson et al. 1999). An alternative hypothesis is that larger-bodied rodents 
and marsupials were selectively extirpated at smaller sites, which were insufficient to sustain their larger home range areas and wider habitat requirements (Lindsted et al. 1986). Also, in a study carried out on nearly the same set of islands, two of the three largerbodied rodent species included in mid-large mammal surveys (Myoprocta acouchy and Cuniculus paca) were absent on the smallest islands (Benchimol and Peres 2015c). This reinforces our findings that the high-end of the 'small-mammal' size spectrum is selectively extirpated on small islands. This finding is particularly interesting given the apparently limited body mass range of these species (10-1,300 g), which still corresponds to two orders of magnitude. The same body mass range is observed between the smallest (acouchi, Myoprocta spp.) and the largest species (tapir, Tapirus spp.) that are typically surveyed in neotropical mid-large mammal assemblages (Paglia et al. 2012). Therefore, our results agree with the sizeselective defaunation gradient observed at larger scales elsewhere (e.g. Canale et al. 2012), which has direct impacts to key ecological interactions (e.g., seed dispersal and insectivory) and ecosystem functioning (Dirzo et al. 2014). A similar but less marked trend was observed for lizards. Perhaps, as the home ranges of these heterotherm species are much smaller than those of mammals for any given body mass (Tamburello et al. 2015), small to mid-size islands could still support a wide range of lizard body sizes (see Fig. 3d).

Matrix tolerance of small mammals further increased towards smaller forest sites indicating that species that can use non-forest matrix areas are able to thrive on smaller islands, which are further characterized by lower tree species richness, and vice-versa for forest-dependent species. Small mammal local extinctions in small forest patches are offset by the incursion of open-habitat species in southern Amazonia (Palmeirim et al. 2020) and the Atlantic Forest (Estavillo et al. 2013). Therefore, matrix tolerance has the potential to predict changes in small mammal communities following habitat loss and fragmentation.

Responses of individual lizard traits reinforced our functional $\alpha$-diversity findings and corroborate a previous study suggesting that lizards persisting on habitat-degraded small islands were comprised of habitat and trophic generalists (see Palmeirim et al. 2017). As expected, species traits associated with persistence were related to greater tolerance to a wider spectrum of environmental conditions, which reflects their heliophile mode and preference for more desiccated forest edges and clearings. Moreover, edge effects are stronger and canopy gaps are proportionally more frequent on smaller islands (Benchimol and Peres 2015b). With the exception of the two smallest islands (each occupied by one heliophobe lizard species), lizard assemblages persisting in these extreme habitat conditions are mostly composed by large-bodied heliophile lizards, which frequently venture into open-area habitats (Lima et al. 2001, Silva et al. 2014). Elsewhere in the tropics, lizard functional diversity declines under habitat disturbance (Berriozabal-Islas et al. 2017), but different species diverge in their responses to altered microclimatic conditions (Lehtinen et al. 2003, Gardner et al. 2007, Suazo-Ortuño et al. 2018).

Functional uniqueness

While certain traits alone may not confer functional uniqueness, their combination can be functionally unique particularly at smaller forest sites. For example, the scansorial marsupial $P$. opossum exhibits high degree of matrix tolerance and is particularly functionally unique (higher $K_{i}$ ) on small forest islands where fewer species persisted. Likewise, the lizard $P$. umbra behaves as a heliophobe but has a long body length. As forest area decreases, these species play a key role by shaping the functional diversity of these communities (Ricotta et al. 2016). These results are consistent with increases in assemblage-level functional redundancy in increasingly larger forest areas (e.g., Bovendorp et al. 2019, Farneda et al. 2020). Also, this was particularly interesting for small mammal species which $\bar{K}_{i}$ was lower than that of lizards, and more functionally redundant at larger forest sites. As forest area is reduced, many small mammal species are gradually extirpated, but their ecological functions may be similarly performed by some of the remaining species (Safi et al. 2011). Functional redundancy has been widely documented in tropical mammals (Safi et al. 2011, Oliveira et al. 2016, Bovendorp et al. 2019), bats (Farneda et al. 2020), and birds (de Coster et al. 2015). In an assemblage in which species share similar traits, if one species goes extinct, it is likely that the remaining species are still able to perform the same functions (Rosenfeld 2002), which is apparently the case of 
small mammals, particularly at larger forest sites in Balbina.

\section{Species (dis)assembly processes}

Taxonomic, functional and phylogenetic $\beta$-diversity of both taxa were mostly partitioned into their $\beta_{\text {rich }^{-}}$ component, suggesting that environmental filtering has shaped small mammal and lizard communities in the insular Balbina landscape. Similar findings were observed for taxonomic and functional diversity of birds and lizards on land-bridge islands in China ( $\mathrm{Si}$ et al. 2015), and bats in primary forest patches embedded in second-growth in the Brazilian Amazon (Farneda et al. 2018). Other studies considering phylogenetic diversity reported the stronger role of deterministic processes in structuring tree (Yang et al. 2015) and bat assemblages across different ecoregions (Aguirre et al. 2016). In our study, deterministic processes shaping small mammal and lizard assemblages are additionally supported by findings on individual trait responses of small mammal and lizard assemblages.

Considering the comparison between similar-sized sites (e.g., small-small and large-large), lizards mostly responded to the environmental filter. This implies that even small differences in forest area are important in structuring lizard assemblages. For small mammals, however, taxonomic $\beta_{\text {repl }}$ values between similarsized sites were higher than those of $\beta_{\text {rich }}$, indicating stronger effects of stochasticity in colonization-extinction rates between such sites, or the effects of environment heterogeneity not fully accounted for. For example, habitat quality on small islands is associated with the intensity of edge effects, which is further related to their location within the reservoir and previous fire history (Benchimol and Peres 2015b). The higher functional redundancy of small mammals compared to lizards also supports the notion that small mammals are generally less affected by environmental gradients. Moreover, although stochasticity can promote limiting similarity (MacArthur and Levins 1967; Tilman 2004), the potential stochasticity associated with taxonomic diversity of small mammals across similar-sized sites did not necessarily result in co-existence of functionally dissimilar species. Instead, both small mammals and lizards played similar functional roles and shared similar phylogeny at similar-sized sites. However, while the subset of lizard species persisting was the same, that of small mammals varied from site to site.

\section{Conservation implications}

Given the surrogacy in the high predictability of TD, FD and PD by forest area, particularly at the local $(\alpha)$ scale, any of these three dimensions of diversity can be used to assess the co-effects of habitat loss and fragmentation (Safi et al. 2011, Dreiss et al. 2015). Yet different aspects of functional diversity provide additional insights. In particular, the use of individual functional traits allows more general predictive ability of which species are likely to go extinct in the aftermath of insular fragmentation, and their consequences for ecosystem functioning. For example, seeds on small islands that sustain only small-bodied mammals may be more likely to be predated rather than dispersed; likewise, insectivory will be higher on mid-sized islands that tend to harbour larger-bodied lizard assemblages, all of which will render impacts on the flow of ecosystem services (Dirzo et al. 2014). Also, as highlighted by patterns of functional uniqueness, the cost associated with individual species extinctions on ecosystem functioning escalated with greater severity of insular fragmentation. Nevertheless, given the inherent taxon-specific differences in responses, we urge caution when considering a single taxon as a surrogate (Wang et al. 2010). For instance, given the higher small mammal functional redundancy at larger forest sites, their persistence therein is particularly important to ensure ecosystem resilience to perturbation (Díaz et al. 2013). In addition, small mammal species composition fluctuates from site to site of similar sizes, so conserving small to mid-sized islands is also important for small mammals, but much less so for lizards.

Over and above the taxon-specific differences, our study demonstrates that small, habitat-degraded islands, harbour reduced taxonomic, functional and phylogenetic diversity of both small mammals and lizards compared to large islands and continuous forests sites. To preserve the multiple dimensions of vertebrate diversity, thereby maintaining the health of the ecosystem, setting-aside large forest tracks should be imperative. This is especially relevant to megadams in lowland tropical forests, which typically inundate extensive areas (Fearnside 2013). In Balbina in particular, $95 \%$ of all 3,546 islands are relatively 
small $(<100 \mathrm{ha})$. Avoiding the creation of myriad small islands should be part of the main guidelines towards sustainable hydropower development. Properly incorporating such guidelines within countrylevel legislation would be a major policy challenge to preclude regional scale biodiversity collapse and associated losses in ecosystem services.

Acknowledgements We thank all 15 volunteers/field assistants who assisted in the field, M. Benchimol and D. Storck-Tonon for their assistance with landscape metrics, the Reserva Biológica do Uatumã and its staff for logistical support, and R. de Fraga and M.N.F. da Silva for their help with species identification. This study was funded by the Amazon Region Protected Areas Program (ARPA), Amazonas Distribuidora de Energia S.A., and Associação Comunidade Waimiri Atroari; Rufford Foundation (Grant Number 13675-1); Idea Wild; and a NERC grant (NE/J01401X/1) awarded to CAP. AFP was funded by European Union's Horizon 2020 research and innovation programme under the Marie Skłodowska-Curie grant agreement No. 792678 and is currently funded under grant agreement No. 854248. FZF was funded by Coordenação de Aperfeiçoamento de Pessoal de Nível Superior (CAPES PrInt - Finance Code 001) scholarship, and MVV was by Fundação de Amparo à Pesquisa do Estado do Rio de Janeiro (FAPERJ, grant E-203.045/2017) and Conselho Nacional de Desenvolvimento Científico e Tecnológico (CNPq, Grants 426.925/2018-1, 312465/2019-0).

Authors' contributions AFP and FZF conceived the ideas; AFP, CAP and MVV defined the sampling design; AFP collected the data; AFP and FZF analysed the data; AFP led the writing of the manuscript. All authors contributed critically to the drafts and gave final approval for publication.

Availability of data and material Data available from previous publications: https://doi.org/10.1007/s00442-0184114-6 (Palmeirim et al. 2018), for small mammal data, and https://doi.org/10.1016/j.biocon.2017.08.002 (Palmeirim et al. 2017), for lizard data.

Code availability The code used to run the analysis of this study is available upon request.

\section{Declarations}

Conflicts of interest The authors declare no conflict of interest nor competing interest.

Ethical approval Whenever live captures could not be identified in the field, a maximum of five voucher specimens per species per site were collected during the first season and deposited at the Mammal and Herpetofauna Collections of the Instituto Nacional de Pesquisas da Amazônia (INPA), in Manaus, Brazil. This study was approved by the appropriate Brazilian government agency (SISBIO license No. 39187-4).
Consent to participate All authors agree in participating in this manuscript.

Consent for publication All authors agree with the publication of this manuscript.

Open Access This article is licensed under a Creative Commons Attribution 4.0 International License, which permits use, sharing, adaptation, distribution and reproduction in any medium or format, as long as you give appropriate credit to the original author(s) and the source, provide a link to the Creative Commons licence, and indicate if changes were made. The images or other third party material in this article are included in the article's Creative Commons licence, unless indicated otherwise in a credit line to the material. If material is not included in the article's Creative Commons licence and your intended use is not permitted by statutory regulation or exceeds the permitted use, you will need to obtain permission directly from the copyright holder. To view a copy of this licence, visit http://creativecommons.org/licenses/by/4.0/.

\section{References}

Aguirre-Gutiérrez J, Malhi Y, Lewis SL, Fauset S, Adu-Bredu S, Affum-Baffoe K, Baker TR, Gvozdevaite A, Hubau W, Moore S, Peprah T, Ziemińska K, Phillips OL, Oliveras I (2020) Long-term droughts may drive drier tropical forests towards increased functional, taxonomic and phylogenetic homogeneity. Nat Comm 11:1-10

Aguirre LF, Montaño-Centellas FA, Gavilanez MM, Stevens RD (2016) Taxonomic and phylogenetic determinants of functional composition of Bolivian bat assemblages. PLoS ONE 11:e0158170

Ávila-Pires TC (1995) Lizards of brazilian amazonia (Reptilia: Squamata). Zoologische verhandelingen 299:1-706

Bartoń K (2016) MuMIn: multi-model inference. R package version 1.15 .6

Baselga A, Orme CDL (2012) betapart: an R package for the study of beta diversity. Methods Ecol Evol 3:808-812

Beaupre SJ, Jacobson ER, Lillywhite HB, Zamudio K (2004) Guidelines for use of live amphibians and reptiles in field and laboratory research. American Society of Ichthyologists and Herpetologists, USA

Benchimol M, Peres CA (2015a) Widespread forest vertebrate extinctions induced by a mega hydroelectric dam in lowland Amazonia. PLoS ONE 10:e0129818

Benchimol M, Peres CA (2015b) Edge-mediated compositional and functional decay of tree assemblages in Amazonian forest islands after 26 years of isolation. $\mathrm{J}$ Ecol 103:408-420

Benchimol M, Peres CA (2015c) Predicting local extinctions of Amazonian vertebrates in forest islands created by a mega dam. Biol Conserv 187:61-72

Berriozabal-Islas C, Badillo-Saldaña LM, Ramírez-Bautista A, Moreno CE (2017) Effects of habitat disturbance on lizard functional diversity in a tropical dry forest of the Pacific Coast of Mexico. Trop Conserv Sci 10:1940082917704972 
Botta-Dukát Z (2005) Rao's quadratic entropy as a measure of functional diversity based on multiple traits. J Veg Sci 16:533-540

Bovendorp RS, Brum FT, McCleery RA, Baiser B, Loyola R, Cianciaruso MV, Galetti M (2019) Defaunation and fragmentation erode small mammal diversity dimensions in tropical forests. Ecography 42:23-35

Burnham KP, Anderson DR (2002) A practical informationtheoretic approach. Model selection and multimodel inference, 2nd edn. Springer, New York

Canale GR, Peres CA, Guidorizzi CE, Gatto CAF, Kierulff MCM (2012) Pervasive defaunation of forest remnants in a tropical biodiversity hotspot. PLoS One 7:e41671

Cardoso P, Rigal F, Carvalho JC (2015) BAT-Biodiversity Assessment Tools, an R package for the measurement and estimation of alpha and beta taxon, phylogenetic and functional diversity. Methods Ecol Evol 6:232-236

Cardoso P, Rigal F, Carvalho JC, Fortelius M, Borges PAV, Podani J, Schmera D (2014) Partitioning taxon, phylogenetic and functional beta diversity into replacement and richness difference components. J Biogeogr 41:749-761

Carvalho JC, Cardoso P, Gomes P (2012) Determining the relative roles of species replacement and species richness differences in generating beta-diversity patterns. Glob Ecol Biogeogr 21:760-771

CEUA-CCS UFRJ (2010) Comissão de Ética no Uso de Animais em Pesquisas da Universidade Federal do Rio de Janeiro. https://www.ccs.ufrj.br/conteudos/ceua. Accessed 1 Nove 2019

Chase JM, Blowes SA, Knight TM, Gerstner K, May F (2020) Ecosystem decay exacerbates biodiversity loss with habitat loss. Nature 584:238-243

Cosson JF, Ringuet S, Claessens O, De Massary JC, Dalecky A, Villiers JF, Granjon L, Pons JM (1999) Ecological changes in recent land-bridge islands in French Guiana, with emphasis on vertebrate communities. Biol Conserv 91:213-222

Dainese M, Lepš J, de Bello F (2015) Different effects of elevation, habitat fragmentation and grazing management on the functional, phylogenetic and taxonomic structure of mountain grasslands. Perspect. Plant Ecol Evol Syst 17:44-53

De Coster G, Banks-Leite C, Metzger JP (2015) Atlantic forest bird communities provide different but not fewer functions after habitat loss. Proc R Soc B 282:20142844

Debastiani VJ, Pillar VD (2012) SYNCSA—R tool for analysis of metacommunities based on functional traits and phylogeny of the community components. Bioinformatics 28:2067-2068

Devictor V, Julliard R, Jiguet F (2008) Distribution of specialist and generalist species along spatial gradients of habitat disturbance and fragmentation. Oikos 117:507-514

Díaz S, Purvis A, Cornelissen JH, Mace GM, Donoghue MJ, Ewers RM, Jordano P, Pearse WD (2013) Functional traits, the phylogeny of function, and ecosystem service vulnerability. Ecol Evol 3:2958-2975

Dirzo R, Young HS, Galetti M, Ceballos G, Isaac NJ, Collen B (2014) Defaunation in the Anthropocene. Science 345:401-406

Dreiss LM, Burgio KR, Cisneros LM, Klingbeil BT, Patterson BD, Presley SJ, Willig MR (2015) Taxonomic functional and phylogenetic dimensions of rodent biodiversity along an extensive tropical elevational gradient. Ecography 38(9):876-888

ESRI (2018) ArcMap 10.1. Environmental Systems Research Institute Inc., Redlands

Estavillo C, Pardini R, da Rocha PLB (2013) Forest loss and the biodiversity threshold: an evaluation considering species habitat requirements and the use of matrix habitats. PLoS ONE 8:e82369

Faith DP (1992). Conservation evaluation and phylogenetic diversity. Biol Conserv 61:1-10

Farneda FZ, Rocha R, López-Baucells A, Groenenberg M, Silva I, Palmeirim JM, Bobrowiec PED, Meyer CFJ (2015) Trait-related responses to habitat fragmentation in Amazonian bats. J Appl Ecol 52:1381-1391

Farneda FZ, Rocha R, López-Baucells A, Sampaio EM, Palmeirim JM, Bobrowiec PED, Grelle CEV, Meyer CFJ (2018) Functional recovery of Amazonian bat assemblages following secondary forest succession. Biol Conserv 218:192-199

Farneda FZ, Grelle CE, Rocha R, Ferreira DF, López-Baucells A, Meyer CF (2020) Predicting biodiversity loss in island and countryside ecosystems through the lens of taxonomic and functional biogeography. Ecography 43:97-106

Fearnside PM (2013) Hidrelétricas na Amazônia: impactos e tomada de decisão. In: Val AL, Santos GM (eds) Grupo de Estudos Estratégicos Amazônicos (GEEA), Tomo VI. Instituto Nacional de pesquisas da Amazônia (INPA), Manaus, Amazonas, pp 43-60 87-91

FUNCATE/INPE/ANEEL (2000) Mapeamento por satélite das áreas inundadas por reservatórios de hidrelétricas brasileiras. Unpublished Report. Convênio FUNCATE/INPE/ ANEEL, São Paulo

Gardner TA, Ribeiro-Junior MA, Barlow JOS, Ávila-Pires TCS, Hoogmoed MS, Peres CA (2007) The value of primary, secondary, and plantation forests for a neotropical herpetofauna. Conserv Biol 21:775-787

Gibson L, Lynam AJ, Bradshaw CJ, He F, Bickford DP, Woodruff DS, Bumrungsri S, Laurance WF (2013) Near-complete extinction of native small mammal fauna 25 years after forest fragmentation. Science 341:1508-1510

Graham CH, Fine PV (2008) Phylogenetic beta diversity: linking ecological and evolutionary processes across space in time. Ecol Lett 11:1265-1277

Guisan A, Edwards TC Jr, Hastie T (2002) Generalized linear and generalized additive models in studies of species distributions: setting the scene. Ecol Model 157:89-100

Haddad NM, Brudvig LA, Clobert J, Davies KF, Gonzalez A, Holt RD, Lovejoy TE, Sexton JO, Austin MP, Collins CD, Cook WM, Damschen EI, Ewers RM, Foster BL, Jenkins CN, King AJ, Laurance WF, Levey DJ, Margules CR, Melbourne BA, Nicholls AO, Orrock JL, Song D, Townshend JR (2015) Habitat fragmentation and its lasting impact on Earth's ecosystems. Sci Adv 1:e1500052

IBAMA (1997) Plano de Manejo Fase I: Reserva Biológica do Uatumã. Eletronorte/IBAMA. Brasília/DF/Brazil. http:// www.icmbio.gov.br. Accessed 1 Jan 2019

IUCN (2020) The IUCN Red List of Threatened Species. Version 2020-2. https://www.iucnredlist.org. Accessed 1 June 2020 
Jones IL, Bunnefeld N, Jump AS, Peres CA, Dent DH (2016) Extinction debt on reservoir land-bridge islands. Biol Conserv 199:75-83

Jones KE, Bielby J, Cardillo M, Fritz SA, O’Dell J, Orme CD, Safi K, Sechrest W, Boakes EH, Carbone C, Connolly C (2009) PanTHERIA: a species-level database of life history, ecology, and geography of extant and recently extinct mammals: Ecological Archives E090-184. Ecology 90:2648-2648

Laliberté E, Legendre P (2010) A distance-based framework for measuring functional diversity from multiple traits. Ecology 91:299-305

Lambert TD, Malcolm JR, Zimmerman BL (2006) Amazonian small mammal abundances in relation to habitat structure and resource abundance. J Mammal 87:766-776

Lavorel S, Grigulis K, McIntyre S, Williams NSG, Garden D, Dorrough J, Berman S, Quétier F, Thébault A, Bonis A (2008) Assessing functional diversity in the fieldmethodology matters! Funct Ecol 22:134-147

Lehtinen RM, Ramanamanjato JB, Raveloarison JG (2003) Edge effects and extinction proneness in a herpetofauna from Madagascar. Biodivers Conserv 12:1357-1370

Lima A, Suárez F, Higuchi I (2001) The effects of selective logging on the lizards Kentropyx calcarata, Ameiva ameiva and Mabuya nigropunctata. Amphibia-Reptilia 22:209-216

Lindstedt SL, Miller BJ, Buskirk SW (1986) Home range, time, and body size in mammals. Ecology 67:413-418

MacArthur RH, Wilson EO (1967) The theory of island biogeography. Press Princeton, Princeton

MacArthur RH, Levins R (1967) The limiting similarity, convergence, and divergence of coexisting species. Am Nat 101:377-385

Maire E, Grenouillet G, Brosse S, Villéger S (2015) How many dimensions are needed to accurately assess functional diversity? A pragmatic approach for assessing the quality of functional spaces. Glob Ecol Biogeogr 24:728-740

Malcolm JR (1991) The small mammals of Amazonian forest fragments: patterns and process. PhD Thesis. University of Florida

Martins M (1991) The lizards of Balbina, Central Amazonia, Brazil: a qualitative analysis of resource utilization. Stud Neotrop Fauna Environ 26:179-190

Matthews TJ, Guilhaumon F, Triantis KA, Borregaard MK, Whittaker RJ (2016) On the form of species-area relationships in habitat islands and true islands. Glob Ecol Biogeogr 25:847-858

McGarigal K, Cushman SA, Ene E (2012) FRAGSTATS v4: spatial pattern analysis program for categorical and continuous maps. https://www.umass.edu/landeco/research/ fragstats/fragstats.html. Accessed 01 Jan 2015

Meynard CN, Devictor V, Mouillot D, Thuiller W, Jiguet F, Mouquet N (2011) Beyond taxonomic diversity patterns: how do $\alpha, \beta$ and $\gamma$ components of bird functional and phylogenetic diversity respond to environmental gradients across France? Glob Ecol Biogeogr 20:893-903

Oliveira BF, Machac A, Costa GC, Brooks TM, Davidson AD, Rondinini C, Graham CH (2016) Species and functional diversity accumulate differently in mammals. Glob Ecol Biogeogr 25:1119-1130
Paglia AP, Fonseca GD, Rylands AB, Herrmann G, Aguiar LM, Chiarello AG, Patton JL (2012) Lista Anotada dos Mamíferos do Brasil. Occasional Papers in Conservation Biology 6, 2nd edn. Conservation International, Arlington, 76p

Palmeirim AF, Santos-Filho M, Peres AC (2020) Marked decline in forest-dependent small mammals following habitat loss and fragmentation in an Amazonian deforestation frontier. PLoS One 15:e0230209

Palmeirim AF, Benchimol M, Vieira MV, Peres CA (2018) Small mammal responses to Amazonian forest islands are modulated by their forest dependence. Oecologia 187:191-204

Palmeirim AF, Vieira MV, Peres CA (2017) Non-random lizard extinctions in land-bridge Amazonian forest islands after 28 years of isolation. Biol Conserv 214:55-65

Petchey OL, Gaston KJ (2002) Functional diversity (FD), species richness and community composition. Ecol Lett 5:402-411

Petchey OL, Evans KL, Fishburn IS, Gaston KJ (2007) Low functional diversity and no redundancy in British avian assemblages. J Anim Ecol 7697:7-985

R Development Core Team (2017) R: A language and environment for statistical computing. R Foundation for Statistical Computing, Vienna, Austria. http://www.R-project. org/

Revell LJ (2012) phytools: an R package for phylogenetic comparative biology (and other things). Methods Ecol Evol $3: 217-223$

Ricotta C, Burrascano S (2009) Testing for differences in beta diversity with asymmetric dissimilarities. Ecol Indic 9:719-724

Ricotta C, de Bello F, Moretti M, Caccianiga M, Cerabolini BE, Pavoine S (2016) Measuring the functional redundancy of biological communities: a quantitative guide. Methods Ecol Evol 7:1386-1395

Rosenfeld JS (2002) Functional redundancy in ecology and conservation. Oikos 98:156-162

Rurangwa ML, Aguirre-Gutiérrez J, Matthews TJ, Niyigaba P, Wayman JP, Tobias JA, Whittaker RJ (2021) Effects of land-use change on avian taxonomic, functional and phylogenetic diversity in a tropical montane rainforest. Divers Distrib. https://doi.org/10.1111/ddi.13364

Safi K, Cianciaruso MV, Loyola RD, Brito D, Armour-Marshall K, Diniz-Filho JAF (2011) Understanding global patterns of mammalian functional and phylogenetic diversity. Philos Trans R Soc B 3662:536-2544

Sala OE, Chapin FS, Armesto JJ, Berlow E, Bloomfield J, Dirzo R, Huber-Sanwald E, Huenneke LF, Jackson RB, Kinzig A, Leemans R (2000) Global biodiversity scenarios for the year 2100. Science 287:1770-1774

Salgado-Luarte C, Escobedo VM, Stotz GC, Rios RS, Arancio G, Gianoli E (2019) Goat grazing reduces diversity and leads to functional, taxonomic, and phylogenetic homogenization in an arid shrubland. Land Degrad Dev 30:178-189

Si X, Baselga A, Ding P (2015) Revealing beta-diversity patterns of breeding bird and lizard communities on inundated land-bridge islands by separating the turnover and nestedness components. PLoS One 10:e0127692

Si X, Cadotte MW, Zeng D, Baselga A, Zhao Y, Li J, Wu Y, Wang S, Ding P (2017) Functional and phylogenetic 
structure of island bird communities. J Anim Ecol 86:532-542

Sikes RS (2016) 2016 Guidelines of the American Society of Mammalogists for the use of wild mammals in research and education. J Mammal 97:663-688

Silva DJ, Santos-Filho M, Canale GR (2014) The importance of remnant native vegetation of Amazonian submontane forest for the conservation of lizards. Braz J Biol 74:523-528

Smiley TM, Title PO, Zelditch ML, Terry RC (2020) Multidimensional biodiversity hotspots and the future of taxonomic, ecological and phylogenetic diversity: A case study of North American rodents. Glob Ecol Biogeogr 29:516-533

Suazo-Ortuño I, Benítez-Malvido J, Marroquín-Páramo J, Soto Y, Siliceo H, Alvarado-Díaz J (2018) Resilience and vulnerability of herpetofaunal functional groups to natural and human disturbances in a tropical dry forest. Forest Ecol Manag 426:145-157

Tabarelli M, Lopes AV, Peres CA (2008) Edge-effects drive tropical forest fragments towards an early-successional system. Biotropica 40:657-661

Tamburello N, Côté I, Dulvy NK (2015) Energy and the scaling of animal space use. Am Nat 186:196-211

Terborgh J, Lopez L, Nuñez P, Rao M, Shahabuddin G, Orihuela G, Riveros M, Ascanio R, Adler GH, Lambert TD, Balbas L (2001) Ecological meltdown in predator-free forest fragments. Science 294:1923-1926

Tilman D (2004) Niche tradeoffs, neutrality, and community structure: a stochastic theory of resource competition, invasion, and community assembly. Proc Natl Acad Sci USA 101:10854-10861

Tonini JFR, Beard KH, Ferreira RB, Jetz W, Pyron RA (2016) Fully-sampled phylogenies of squamates reveal evolutionary patterns in threat status. Biol Conserv 204:23-31

Tucker CM, Davies TJ, Cadotte MW, Pearse WD (2018) On the relationship between phylogenetic diversity and trait diversity. Ecology 99:1473-1479

Upham NS, Esselstyn JA, Jetz W (2019) Inferring the mammal tree: Species-level sets of phylogenies for questions in ecology, evolution, and conservation. PLoS Biol 17:e3000494

Veron S, Davies TJ, Cadotte MW, Clergeau P, Pavoine S (2017) Predicting loss of evolutionary history: Where are we? Biol Rev 92:271-291
VertLife (2020) VertLife: Phylogeny subsets. https://vertlife. org/phylosubsets/. Accessed 1 June 2020

Violle C, Navas ML, Vile D, Kazakou E, Fortunel C, Hummel I, Garnier E (2007) Let the concept of trait be functional! Oikos 116:882-892

Vitt LJ, Caldwell JP (2014) Herpetology: an introductory biology of amphibians and reptiles. Elsevier, Norman

Warton DI, Blanchet FG, O'Hara RB, Ovaskainen O, Taskinen S, Walker SC, Hui FKC (2015) So many variables: joint modeling in community ecology. Trends Ecol Evol 30:766-779

Wang Y, Bao Y, Yu M, Xu G, Ding P (2010) Nestedness for different reasons: the distributions of birds, lizards and small mammals on islands of an inundated lake. Divers Distrib 16:862-873

Webb CO, Ackerly DD, McPeek MA, Donoghue MJ (2002) Phylogenies and community ecology. Annu Rev Ecol Evol Syst 33:475-505

Weiss KC, Ray CA (2019) Unifying functional trait approaches to understand the assemblage of ecological communities: synthesizing taxonomic divides. Ecography 42:2012-2020

Whittaker RH (1972) Evolution and measurement of species diversity. Taxon 21:213-251

Wilman H, Belmaker J, Simpson J, de la Rosa C, Rivadeneira MM, Jetz W (2014) EltonTraits 1.0: species-level foraging attributes of the world's birds and mammals. Ecological Archives E 095-178 Ecology 95:2027-2027

Wood S, Wood MS (2015) Package 'mgcv'. R package version, 1,29

Yang J, Swenson NG, Zhang G, Ci X, Cao M, Sha L, Li J, Slik JWF, Lin L (2015) Local-scale partitioning of functional and phylogenetic beta diversity in a tropical tree assemblage. Sci Rep 5:12731

Zhao Y, Dunn RR, Zhou H, Si X, Ding P (2020) Island area, not isolation, drives taxonomic, phylogenetic and functional diversity of ants on land-bridge islands. J Biogeogr 47:1627-1637

Publisher's Note Springer Nature remains neutral with regard to jurisdictional claims in published maps and institutional affiliations. 